\title{
ARTICLE OPEN Spatial trends in United States tornado frequency
}

\author{
Vittorio A. Gensini (D) ${ }^{1}$ and Harold E. Brooks ${ }^{2}$
}

Severe thunderstorms accompanied by tornadoes, hail, and damaging winds cause an average of 5.4 billion dollars of damage each year across the United States, and 10 billion-dollar events are no longer uncommon. This overall economic and casualty risk-with over 600 severe thunderstorm related deaths in 2011-has prompted public and scientific inquiries about the impact of climate change on tornadoes. We show that national annual frequencies of tornado reports have remained relatively constant, but significant spatially-varying temporal trends in tornado frequency have occurred since 1979. Negative tendencies of tornado occurrence have been noted in portions of the central and southern Great Plains, while robust positive trends have been documented in portions of the Midwest and Southeast United States. In addition, the significant tornado parameter is used as an environmental covariate to increase confidence in the tornado report results.

npj Climate and Atmospheric Science (2018)1:38; doi:10.1038/s41612-018-0048-2

\section{INTRODUCTION}

Recent trends in global and United States temperature have provoked questions about the impact on frequency, intensity, timing, and location of tornadoes. When removing many nonmeteorological factors, it is shown that the annual frequency of United States tornadoes through the most reliable portions of the historical record has remained relatively constant. ${ }^{1-4}$ The most notable trends in tornado frequency are associated with increasing annual variability and a recent tendency for more tornadoes on any given tornado day. ${ }^{5-9}$ There has also been a measurable shift in the annual timing of tornado season, but it is currently unknown if this is due to rising global temperatures or natural variability. ${ }^{10,11}$ Two recent studies show increased tornado frequency in the eastern United States and decreased activity generally in the central United States, but analyses were limited to epochs. ${ }^{7,12}$ In addition, decreasing tornado frequency trends in the Great Plains and increasing trends in the Southeast are present in annual counts of $E(F) 1+$ tornadoes. $^{13}$ Despite these changes, detecting spatial shifts in tornado frequency has proved challenging given the relatively small spatial and temporal scales associated with tornado-producing thunderstorms and the welldocumented deficiencies accompanying the tornado reporting database. ${ }^{1}$ The work herein seeks to examine spatial trends in tornado environments and tornado frequency at finer-scale resolutions in space and time.

These deficiencies have motivated researchers to focus on developing and analyzing atmospheric derived indices relating environmental conditions to tornado occurrence. Such indices are often used in an ingredients-based approach commonly utilized in operational weather forecasting. ${ }^{14}$ The significant tornado parameter (STP) is one such index, originally designed as a statistical discriminator between non-tornado and significant ([E]F2 or greater using the Fujita damage scale) tornado environments. ${ }^{15}$ STP is a commonly used operational weather forecasting index, but no research has used STP to examine the covariant relationship with aspects of the United States tornado report climatology.
A derived covariate, such as STP, is complementary to tornado reports for climatological studies. For example, it has been shown that variables like storm relative helicity and convective precipitation adequately represent United States monthly tornado frequency. ${ }^{16}$ Reports are subject to a human reporting process, whereas environmental covariates allow for an objective modelderived climatology. One major limitation of the covariate methodology for tornadoes is the lack of accounting for a thunderstorm initiation metric. It is well documented that tornadoes occur in environments characteristic of adequate vertical wind shear, relatively high surface water vapor mixing ratios, low static stability, and directional change in the lowest 1$\mathrm{km}$ of tropospheric wind. ${ }^{17,18}$ Yet, even with a supportive atmosphere, thunderstorms may not form in the absence of an initial lifting mechanism needed to commence the convective process. The space and time scales of various lifting sources are often below the spatial scale of current reanalysis observation capabilities, and thus, not accounted for by most covariate environmental metrics. This often leads to an overestimation of favorable tornado environments and a lack of explanatory capability regarding observed tornado reports, especially when convective inhibition is present. ${ }^{19}$

Recent increases in computational efficiency have led several studies to explicitly depict severe convective storms in convective permitting regional climate model configurations to evade the previously discussed environmental caveats. ${ }^{20-25}$ These dynamical downscaling approaches (sometimes referred to as model telescoping) have proven reliable for the replication of spatial frequency and temporal timing of the annual peak of boreal severe weather activity. Potential changes in characteristics of late $21^{\text {st }}$ century severe weather activity have also been posited by these methods. However, due to the resource intensive nature of these approaches, long model-derived climatologies are often unfeasible and it is not yet clear if the explanatory capability is significantly better than environments to justify the resources necessary to conduct such simulations.

\footnotetext{
${ }^{1}$ Northern Illinois University, DeKalb, IL 60115, USA and ${ }^{2}$ National Severe Storms Laboratory, Norman, OK 73072, USA
}

Correspondence: Vittorio A. Gensini (vgensini@niu.edu)

Received: 30 May 2018 Revised: 12 September 2018 Accepted: 24 September 2018

Published online: 17 October 2018 


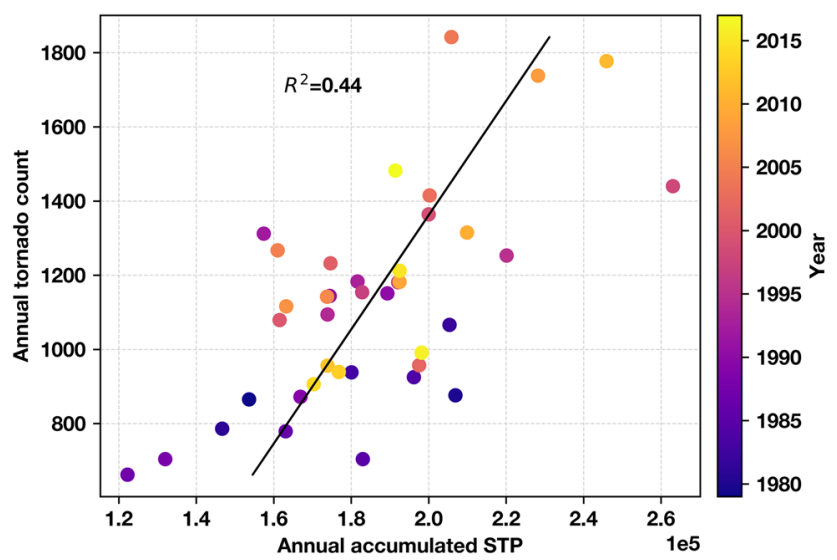

Fig. 1 Scatter plot of United States annual tornado counts vs. United States annual accumulated significant tornado parameter (1979-2017) from NARR

This research focuses on an environmental covariate approach to examine potential changes in United States tornado frequency. In particular, we begin by analyzing an aggregated covariate methodology in an attempt to explain the variance associated with monthly and annual United States tornado reports. We further examine the spatio-temporal changes in this covariate over the past $\sim 40$ years. This allows us to draw conclusions about the regional trends in frequency of tornado environments. We conclude by comparing the covariate trend analyses to actual tornado reporting trends to strengthen the presented results. Ultimately, our research highlights that trends in United States tornado frequency are regional in nature and this change in physical risk has implications for tornado exposure and vulnerability.

\section{RESULTS}

Despite the aforementioned environmental caveats, annual accumulated diurnal max STP is a statistically significant covariate to annual United States tornado reports (Fig. 1). This degree of explanatory power (44\% of the variance in annual tornado counts is explained by accumulated diurnal maximum STP) suggests that STP may be used as a climatological proxy for annual tornado report counts. At the monthly scale, accumulated STP exhibits a seasonal trend in explanatory power. Monthly standardized anomalies of accumulated diurnal maximum STP for January, February, March, May, and December all explain roughly half of the variance associated with the standardized anomaly of monthly United States tornado counts (Fig. 2). August displays a minimum in variance explanation (9\%), and it is speculated this is a function of the mesoscale nature of late boreal summer tornado environments and larger contributions to the monthly count climatologies from tropical storms and hurricanes. Standardized anomaly regression slopes reveal that monthly accumulated STP is a conservative estimator of monthly tornado counts, and this bias is greatest in the boreal summer (Fig. 2). The null hypothesis of, "Monthly accumulated STP does not explain statistically significant amounts of variance in monthly tornado counts" was rejected at the 0.01 significance level for all months except August. Thus, the STP covariate can be applied at the monthly scale, but caution should be used due to the seasonal changes in the coefficient of determination and level of statistical significance.

Examining annual tornado report counts and accumulated annual STP through time confirm this explanatory relationship and give further confidence in the use of STP as a climatological tornado report proxy (Fig. 3). Both tornado counts and STP indicate a slight positive trend through time over the analysis

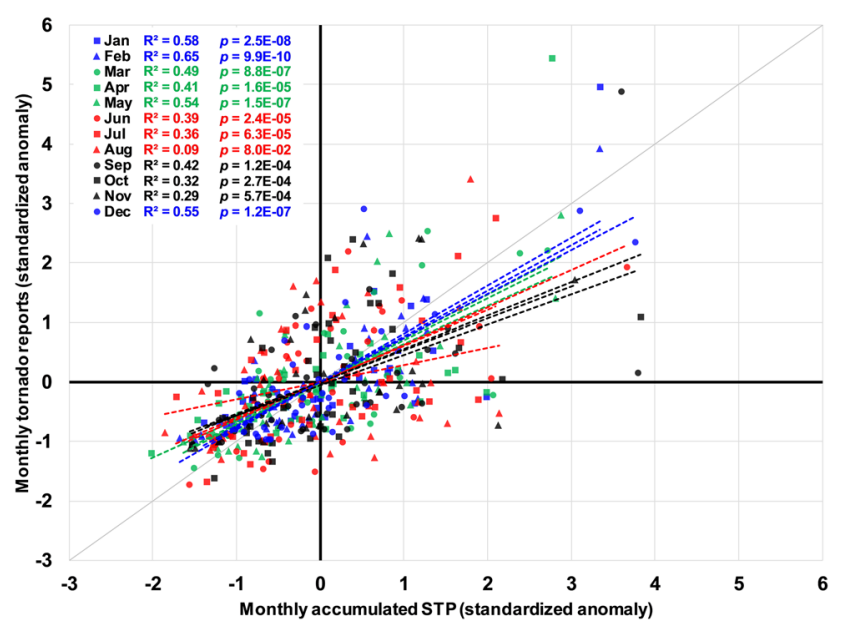

Fig. 2 1979-2017 Unites States monthly tornado reports and accumulated diurnal maximum STP (expressed here as a standardized anomaly by month) from NARR. Regression $r^{2}$ and $p$ values are listed next to their respective months

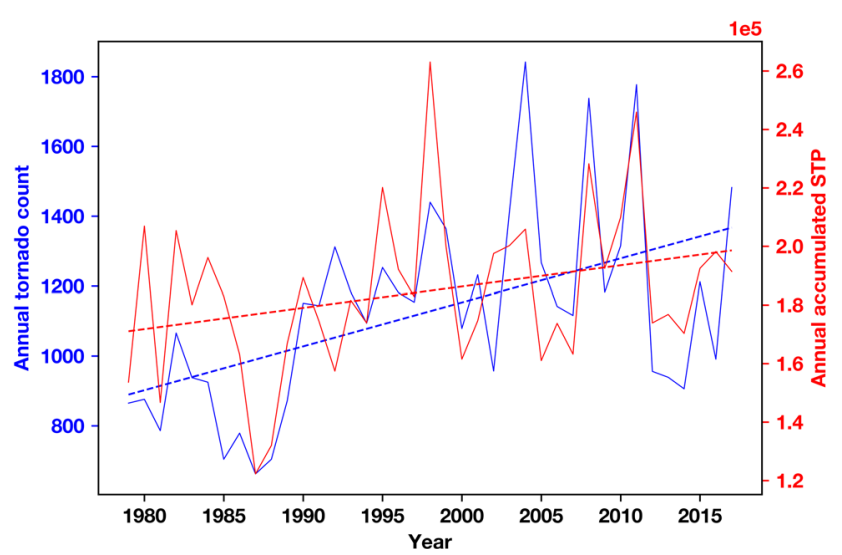

Fig. 3 Interannual variability of United States tornado reports (blue; axis left) and the United States annual sum of daily max significant tornado parameter (red; axis right) from NARR

period, which starts at the beginning of the modern Geostationary Operational Environmental Satellite (GOES) era. Consistent tornado reporting data exists back to the early 1950s, but there are currently no datasets that allow for the space and time scales necessary to adequately retroactively compute STP back to 1950, and hence, we are limited here to the analysis period 1979-2017. Most of the increase in tornado reporting is observed from the late 1980 s to the early 2000 s, with a steady or even declining trend thereafter which is consistent with previous research. ${ }^{3}$

Of greatest interest here is the potential for shifts in the spatial location of tornado frequency. Research has identified evidence of a "Dixie Alley," which represents an eastward extension of the traditional "Tornado Alley" in the central Great Plains. ${ }^{26}$ However, this could be due to the techniques used to smooth reports in space and time. ${ }^{27}$ An eastward shift in tornado frequency was also suggested, but results were limited to two arbitrary regions, coarse spatial environmental covariates, and lacked a robust environmental tornado report proxy such as STP. ${ }^{12,13}$ Using Theil-Sen slope analysis-a robust linear trend estimator which is insensitive to outliers-and Kendall's $\tau$ test for statistical significance, we show a robust downward trend in the annual accumulation of STP across the central and southern Great Plains. Meanwhile, a robust upward trend is found in portions of the Southeast, Midwest, and Northeast (Fig. 4). No significant increase (decrease) in tornado environments is observed west (east) of the $95^{\text {th }}$ meridian. We 

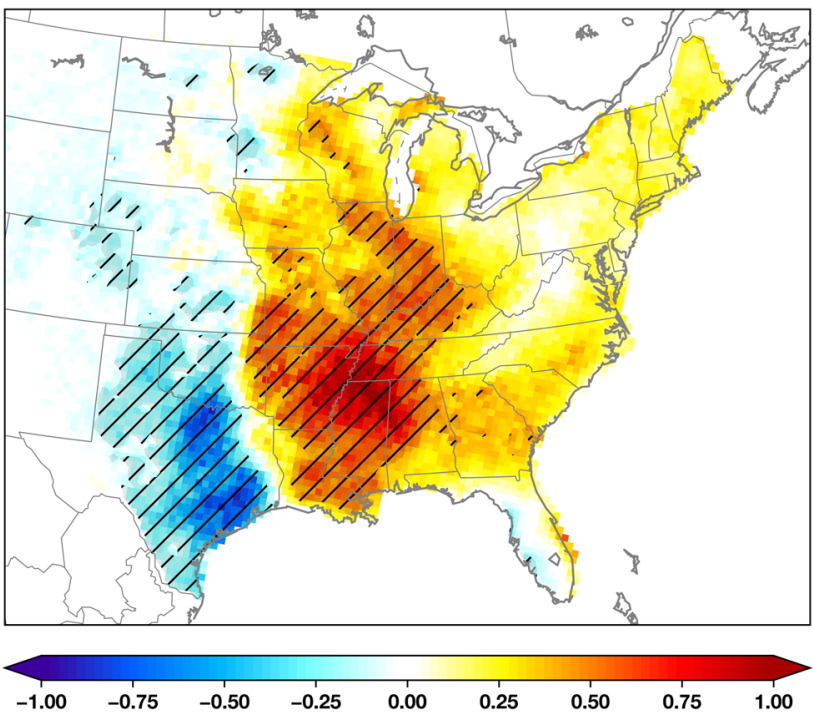

Fig. 4 Theil-Sen slope analysis of 1979-2017 annual grid-point sum of daily max STP from NARR. $p$ values are hatched at values $\leq$ 0.05 significance using Kendall's $\tau$ statistic. Slope units are sum of daily max STP per year

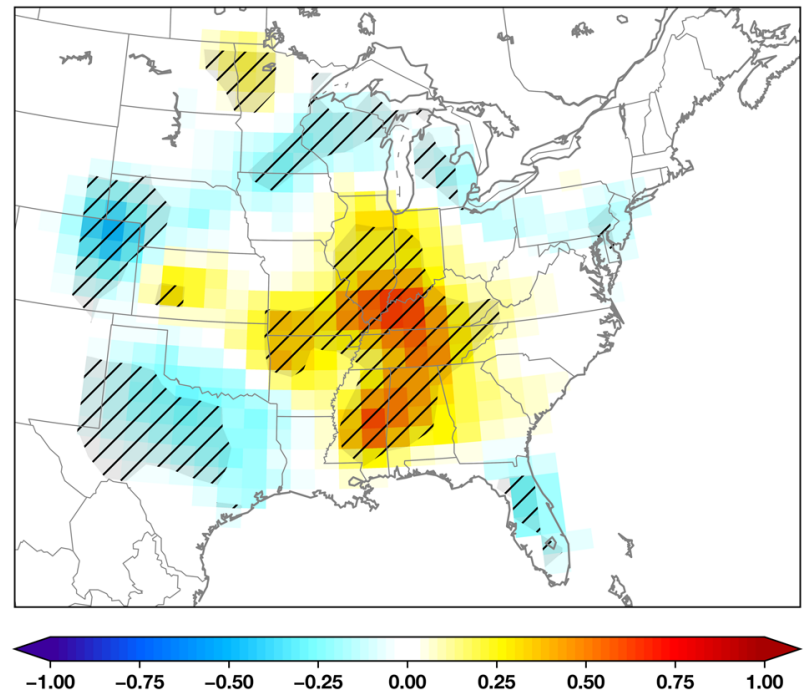

Fig. 5 Theil-Sen slope analysis of 1979-2017 annual gridded tornado reports. $p$ values are hatched at values $\leq 0.05$ significance using Kendall's $\tau$ statistic. Slope units are reports per year ${ }^{*} 10^{-1}$

believe these trends in tornado environments are significant and have not been documented with this level of detail by previous research.

Given these environmental tendencies, one would also suspect to find such evidence of trends in tornado reports given the explanatory power of the STP covariate. Indeed, significant trends in the spatial frequency of annual tornado reports are found over the analysis period (Fig. 5). Both tornado reports and environments indicate significant decreasing trends in frequency over portions of Texas, Oklahoma, and northeast Colorado. Agreement in the sign of the Theil-Sen slope is also noted for significant increasing trends in portions of Mississippi, Alabama, Arkansas, Missouri, Illinois, Indiana, Tennessee, and Kentucky. We are most confident about the trends in these areas, where both tornado reports and environments share the same significant sign of TheilSen's slope. Confidence in the trends of tornado frequency are reduced in areas where the sign of Theil-Sen's slope is opposite or do not share statistical significance. For example, significant increases in tornado reporting trends are found across Kansas, but environments indicate a neutral or downward trend. Additionally, tornado environments indicate a robust increasing trend in portions of Arkansas and Louisiana that are not supported by tornado reporting trends. We cannot offer a physical reason for these discrepancies at the current time, but they may be a function of non-continuous regional/seasonal efficiencies of the STP covariate (e.g., biases shown in Fig. 2) and biases in the tornado report database. We speculate the non-continuous regional/seasonal efficiencies of STP are a function of convective initiation and forcing for ascent. In addition, STP was designed with the intention of evaluating environments favorable for rightmoving supercells in the Great Plains of the U.S. and not necessarily non-mesocyclone tornadoes. ${ }^{15,28}$ However, results associated with reports herein are generally consistent with an increasing trend found in the Southeast United States due to a greater propensity for tornado outbreaks east of the Mississippi River. ${ }^{29,30}$

Further examination reveals that spatial trends in tornado environment frequency are modulated by seasons (Fig. 6). Positive trends in tornado environment frequency are shown to progress northward through the annual cycle. Most of the decreasing trends across Texas are due to the months of March, April, and May (Fig. 6b), and most of the Great Plains has shown a decreasing trend in tornado environments during June, July, and August (Fig. $6 c$ ). It should be noted that our results do not indicate that maximum United States tornado environment and report frequency is no longer in the Great Plains. Rather, we demonstrate there has been a robust downward trend of tornado environments and reports in portions of the Great Plains concurrent with a simultaneous robust increasing trend in areas surrounding the Mississippi River Valley and the Midwest.

\section{DISCUSSION}

The presented trends in spatial tornado frequency are important for understanding the tornado as a hazard, which involves examining the comingling of physical risk (i.e., climatological probability of a tornado report) and societal vulnerability (e.g., population density). Such increases in tornado frequency across the Mid-South juxtapose with an already vulnerable population to tornadoes. In fact, this geographic area of the United States already represents a maximum in the occurrence of casualties associated with tornadoes. ${ }^{31}$ Climate downscaling and societal vulnerability studies also highlight the Mid-South as having the greatest potential for increased tornado disasters by the end of the century. ${ }^{23,25,32,33}$

Economic losses associated with tornadoes will continue to increase in future years, both due to the spatial changes presented herein and the expanding footprint of the built environment. ${ }^{34}$ It is noted that the impacts associated with projected $21^{\text {st }}$ century increases in tornado frequency are outweighed by projected growth in the human-built environment. However, the combination of an increase in risk and exposure could lead to a threefold increase in tornado disaster potential. ${ }^{32,33}$ Thus, it is important to continue monitoring the presented physical trends in tornado frequency and recognize that they have consequences for increases in tornado disaster potential.

At this point, it is unclear whether the observed trends in tornado environment and report frequency are due to natural variability or being altered by anthropogenic forcing on the climate system. Global and regional climate model studies indicate a general increase in severe weather frequency (especially in boreal spring) and variability by the end of the 21 st century in portions of the Midwest and Southeast, suggesting that the trends herein may indeed be due to anthropogenic forcing given the accumulating literature examining tornado/severe weather 

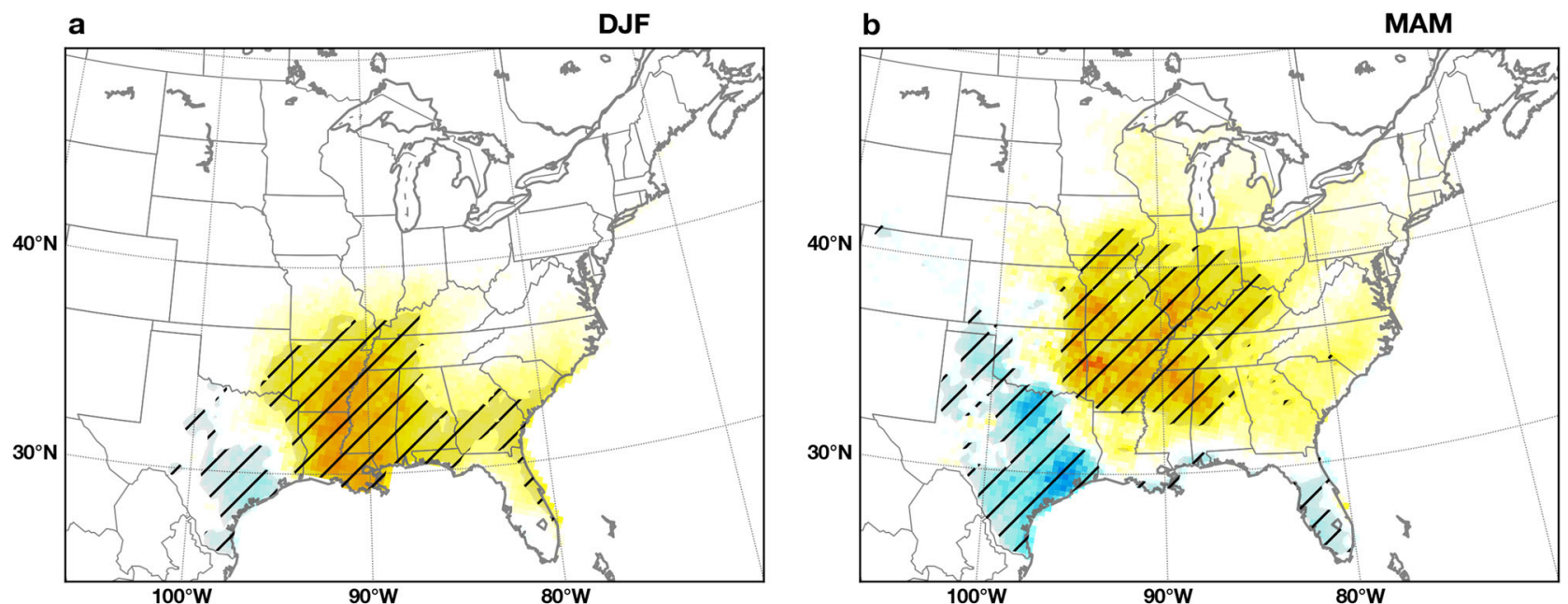

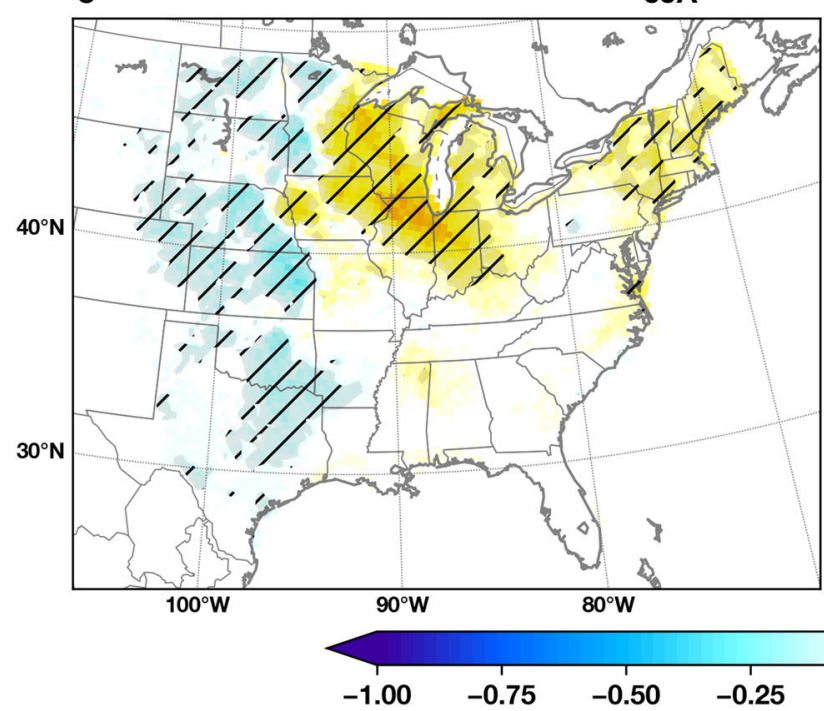

JJA

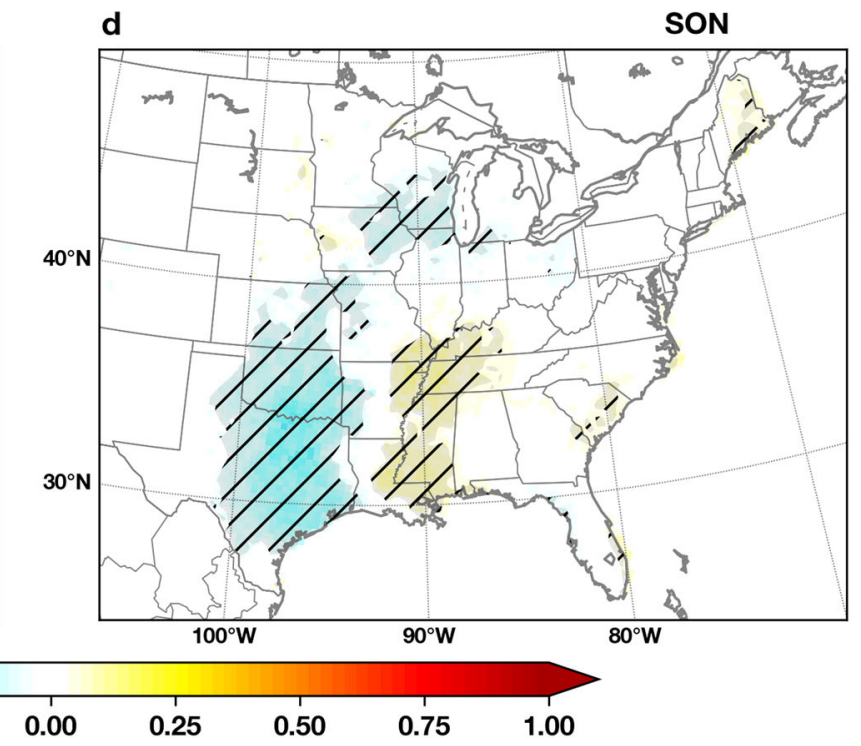

Fig. 6 Theil-Sen slope of 1979-2017 annual grid-point sum of daily max STP for a) December, January, February; b) March, April, May; c) June, July, August; and d) September, October, November. $p$ values are hatched at values $\leq 0.05$ significance using Kendall's $\tau$ statistic. Slope units are sum of daily max STP per year

frequency and variability. ${ }^{3}$ This eastward shift is also consistent with recent work suggesting an eastward shift in the "effective 100 th meridian" as the century progresses. ${ }^{35}$ It is difficult to isolate these natural vs. anthropogenic factors, but perhaps future attribution studies will be able to describe such causal mechanisms.

\section{METHODS}

Tornado data were retrieved from the Storm Prediction Center's online database (described online at http://www.spc.noaa.gov/wcm/\#data] for the period 1979-2017. All tornadoes were used in this analysis. Data from the North American Regional Reanalysis (NARR; ${ }^{36}$ ) was used to calculate the STP (a unitless derived environmental variable) covariate. 3-hourly data were downloaded from the NCAR/UCAR research data archive portal (https://rda.ucar.edu/datasets/ds608.0/) for the period 1979-2017.

STP was calculated following a fixed-layer ${ }^{15}$ approach:

$\mathrm{STP}=\frac{\mathrm{SBCAPE}}{1500} \times \frac{(2000-\mathrm{SBLCL})}{1000} \times \frac{\mathrm{SRH} 01}{150} \times \frac{\mathrm{BWD06}}{20}$

using surface-based convective available potential energy (SBCAPE), surface-based lifting condensation level (SBLCL), $0-1 \mathrm{~km}$ storm relative helicity (SRH01), and 0-6 km bulk wind difference (BWD06). Since NARR data use an isobaric vertical coordinate system, data were vertically interpolated from NARR isobaric levels to AGL height coordinates for AGL calculations (e.g., 0-6 km). In addition, STP was masked in the presence of convective inhibition $<-50 \mathrm{~J} \mathrm{~kg}^{-1}$ in an attempt to examine environments most favorable for tornadoes. STP was computed on the native NARR $32-$ $\mathrm{km}$ lambert conformal grid. An accumulated STP metric was derived as a covariate for comparison to the annual tornado report counts by finding the diurnal (1200-1200 UTC) max STP value from NARR 3-hourly data and summing all CONUS land point daily maximums over the year to create annual accumulation values. 1200-1200 UTC was chosen for the daily cycle to capture diurnally driven supercell and tornado climatology. ${ }^{37}$ Annual diurnal max accumulations were used to explain annual tornado report variability. For monthly regressions, a standardized anomaly was calculated for both monthly tornado counts and monthly accumulation of diurnal maximum STP. Regression slopes of these standardized anomaly relationships were examined to demonstrate monthly explanatory capability, variability, and bias.

For spatial trend analysis of the STP covariate, a Theil-Sen estimator was calculated at each native NARR grid point on the interannual accumulation values. Theil-Sen slope analysis was chosen due its efficient computation and insensitivity to outliers. ${ }^{38}$ Significance of the Theil-Sen slope was assessed using Kendall's $\tau$ statistic and a $p$ value at the 0.05 significance level. Since tornado reports are point objects in space and time-and not gridded-reports were binned in space on a $1^{\circ}$ latitude by $1^{\circ}$ longitude grid using the same lambert conformal projection as NARR data and smoothed in space using a 1- $\sigma$ Gaussian kernel. Theil-Sen slope analysis 
and Kendall's $\tau$ statistic were then calculated on interannual gridded tornado reports using the same methodology for accumulated STP. The authors note that due to the number of statistical tests, familywise error rate, and inherent autocorrelation in time and space of climatological data, such analyses are potentially impacted by the multiple testing problem. ${ }^{38}$

\section{DATA AVAILABILITY}

Tornado reports are available from the storm events database at http://www.spc noaa.gov/wcm/\#data. NARR data were downloaded from the Research Data Archive (RDA) at the National Center for Atmospheric Research (NCAR), Computational and Information Systems Laboratory (CISL) at http://rda.ucar.edu/datasets/ds608.0/.

\section{ACKNOWLEDGMENTS}

Funding for the publication of this manuscript was provided by the Northern Illinois University Open Access Publishing Fund.

\section{AUTHOR CONTRIBUTIONS}

V.A.G. designed research, conducted primary analysis, prepared figures, and wrote the manuscript. H.E.B. assisted with writing and research design.

\section{ADDITIONAL INFORMATION}

Competing interests: The authors declare no competing interests.

Publisher's note: Springer Nature remains neutral with regard to jurisdictional claims in published maps and institutional affiliations.

\section{REFERENCES}

1. Verbout, S. M., Brooks, H. E., Leslie, L. M. \& Schultz, D. M. Evolution of the US tornado database: 1954-2003. Weather Forecast. 21, 86-93 (2006).

2. Kunkel, K. E. et al. Monitoring and understanding trends in extreme storms: state of knowledge. Bull. Am. Meteorol. Soc. 94, 499-514 (2013).

3. Tippett, M. K., Allen, J. T., Gensini, V. A. \& Brooks, H. E. Climate and hazardous convective weather. Curr. Change Rep. 1, 60-73 (2015).

4. Long, J. A., Stoy, P. C. \& Gerken, T. Tornado seasonality in the southeastern United States. Weather Clim. Extrem. 20, 81-91 (2018).

5. Brooks, H. E., Carbin, G. W. \& Marsh, P. T. Increased variability of tornado occurrence in the United States. Science 346, 349-352 (2014).

6. Tippett, M. K. Changing volatility of US annual tornado reports. Geophys. Res. Lett 41, 6956-6961 (2014).

7. Farney, T. J. \& Dixon, P. G. Variability of tornado climatology across the continental United States. Int. J. Climatol. 35, 2993-3006 (2015).

8. Guo, L., Wang, K. \& Bluestein, H. B. Variability of tornado occurrence over the continental United States since 1950. J. Geophys. Res. Atmos. 121, 6943-6953 (2016).

9. Tippett, M. K., Lepore, C. \& Cohen, J. E. More tornadoes in the most extreme US tornado outbreaks. Science 354, 1419-1423 (2016).

10. Long, J. A. \& Stoy, P. C. Peak tornado activity is occurring earlier in the heart of "Tornado Alley". Geophys. Res. Lett. 41, 6259-6264 (2014).

11. Lu, M., Tippett, M. \& Lall, U. Changes in the seasonality of tornado and favorable genesis conditions in the central United States. Geophys. Res. Lett. 42, 4224-4231 (2015).

12. Agee, E., Larson, J., Childs, S. \& Marmo, A. Spatial redistribution of US Tornado activity between 1954 and 2013. J. Appl. Meteorol. Climatol. 55, 1681-1697 (2016).

13. Moore, T. W. Annual and seasonal tornado trends in the contiguous United States and its regions. Int. J. Climatol. 38, 1582-1594 (2018).

14. Johns, R. H. \& Doswell, C. A. III Severe local storms forecasting. Weather Forecast 7, 588-612 (1992).

15. Thompson, R. L., Edwards, R., Hart, J. A., Elmore, K. L. \& Markowski, P. Close proximity soundings within supercell environments obtained from the Rapid Update Cycle. Weather Forecast. 18, 1243-1261 (2003).

16. Tippett, M. K., Sobel, A. H., Camargo, S. J. \& Allen, J. T. An empirical relation between US tornado activity and monthly environmental parameters. J. Clim. 27, 2983-2999 (2014).
17. Rasmussen, E. N. \& Blanchard, D. O. A baseline climatology of sounding-derived supercell and tornado forecast parameters. Weather Forecast. 13, 1148-1164 (1998).

18. Rasmussen, E. N. Refined supercell and tornado forecast parameters. Weather Forecast. 18, 530-535 (2003).

19. Gensini, V. A. \& Ashley, W. S. Climatology of potentially severe convective environments from the North American regional reanalysis.E J. Severe Storms Meteorol. 6, 1-40 (2011).

20. Trapp, R. J., Robinson, E. D., Baldwin, M. E., Diffenbaugh, N. S. \& Schwedler, B. R. Regional climate of hazardous convective weather through high-resolution dynamical downscaling. Clim. Dyn. 37, 677-688 (2011).

21. Mahoney, K., Alexander, M. A., Thompson, G., Barsugli, J. J. \& Scott, J. D. Changes in hail and flood risk in high-resolution simulations over Colorado's mountains. Nat. Clim. Change 125, 125-131 (2012).

22. Gensini, V. A. \& Mote, T. L. Estimations of hazardous convective weather in the United States using dynamical downscaling. J. Clim. 27, 6581-6589 (2014).

23. Gensini, V. A. \& Mote, T. L. Downscaled estimates of late 21 st century severe weather from CCSM3. Clim. Change 129, 307-321 (2015).

24. Robinson, E. D., Trapp, R. J. \& Baldwin, M. E. The geospatial and temporal distributions of severe thunderstorms from high-resolution dynamical downscaling J. Appl. Meteorol. Climatol. 52, 2147-2161 (2013).

25. Hoogewind, K. A., Baldwin, M. E. \& Trapp, R. J. The Impact of climate change on hazardous convective weather in the United States: insight from high-resolution dynamical downscaling. J. Clim. 30, 10081-10100 (2017).

26. Dixon, P. G., Mercer, A. E., Choi, J. \& Allen, J. S. Tornado risk analysis: Is Dixie alley an extension of tornado alley? Bull. Am. Meteorol. Soc. 92, 433-441 (2011).

27. Marsh, P. T. \& Brooks, H. E. Comments on "Tornado risk analysis: is Dixie Alley an extension of Tornado Alley?". Bull. Am. Meteorol. Soc. 93, 405-407 (2012).

28. R. Davies-Jones, R. J., Trapp, H. B. Bluestein, tornadoes, and tornadic storms. in Severe Convective Storms (Charles A. Doswell III eds.) 167-221 (American Meteorological Society, Boston, MA, 2001).

29. Childs, S. J., Schumacher, R. S. \& Allen, J. T. Cold-season tornadoes: climatological and meteorological insights. Weather Forecast. 33, 671-691 (2018).

30. Moore, T. W. On the temporal and spatial characteristics of tornado days in the United States. Atmos. Res. 184, 56-65 (2017).

31. Ashley, W. S. Spatial and temporal analysis of tornado fatalities in the United States: 1880-2005. Weather Forecast. 22, 1214-1228 (2007)

32. Strader, S. M., Ashley, W. S., Pingel, T. J. \& Krmenec, A. J. Projected 21 st century changes in tornado exposure, risk, and disaster potential. Clim. Change 141, 301-313 (2017)

33. Strader, S. M., Ashley, W. S., Pingel, T. J. \& Krmenec, A. J. Observed and projected changes in United States tornado exposure. Weather, Clim., Soc. 9, 109-123 (2017).

34. Ashley, W. S. \& Strader, S. M. Recipe for disaster: How the dynamic ingredients of risk and exposure are changing the tornado disaster landscape. Bull. Am. Meteorol. Soc. 97, 767-786 (2016).

35. Seager, R. et al. Whither the 100th meridian? The once and future physical and human geography of America's Arid-Humid Divide. Part II: the meridian moves east. Earth Interact. 22, 1-24 (2018)

36. Mesinger, F. et al. North American regional reanalysis. Bull. Am. Meteorol. Soc. 87, 343-360 (2006).

37. Kelly, D., Schaefer, J., McNulty, R., Doswell, C. III \& Abbey, R. Jr An augmented tornado climatology. Mon. Weather Rev. 106, 1172-1183 (1978).

38. Wilcox, R. R. Fundamentals of Modern Statistical Methods: Substantially Improving Power And Accuracy. (Springer Science \& Business Media, New York. 2010).

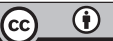

Open Access This article is licensed under a Creative Commons Attribution 4.0 International License, which permits use, sharing, adaptation, distribution and reproduction in any medium or format, as long as you give appropriate credit to the original author(s) and the source, provide a link to the Creative Commons license, and indicate if changes were made. The images or other third party material in this article are included in the article's Creative Commons license, unless indicated otherwise in a credit line to the material. If material is not included in the article's Creative Commons license and your intended use is not permitted by statutory regulation or exceeds the permitted use, you will need to obtain permission directly from the copyright holder. To view a copy of this license, visit http://creativecommons. org/licenses/by/4.0/.
}

(c) The Author(s) 2018 